\title{
Which Is Important: Incision Length or Oncological Outcome?
}

\author{
Baris Yildiz ${ }^{1}$ Mesut Tez ${ }^{1}$
}

Published online: 22 February 2017

(C) Springer Science+Business Media New York 2017

Dear Editor,

We read with great interest the article titled "Comparison of Clinical Outcomes Between Laparoscopic-Assisted and Minilaparotomy Approaches for Colon Cancer." by Liu Z, et al. [1] In this article, authors are comparing outcomes of minilaparotomy and laparoscopy for colon cancer. We think that this study should have included another arm constituting patients who had regular laparotomy regardless of the length of incision. This would give us an idea whether these two "minimal invasive" techniques have a superior oncological outcomes than open colectomy. We also would like to ask the authors what the point was in comparing minilaparotomy but not open technique with laparoscopy as other studies did [2]. This further raises the question whether it is worthwhile to sacrifice better oncological outcomes for the sake of cosmesis or shortened "mean time to first bowel movement".

\author{
Compliance with Ethical Standards \\ Conflicts of Interest The authors declare that they have no conflict of \\ interest.
}

\section{References}

1. Liu Z, Zhou T, Yang G, Zhang G. Comparison of clinical outcomes between laparoscopic-assisted and minilaparotomy approaches for colon cancer. J Gastrointest Cancer. 2017 Feb 3; doi:10.1007/ s12029-017-9923-z.

2. Vennix S, Pelzers L, Bouvy N, Beets GL, Pierie JP, Wiggers T, Breukink S. Laparoscopic versus open total mesorectal excision for rectal cancer. Cochrane Database Syst Rev. 2014;4: CD005200. doi:10.1002/14651858.CD005200.pub3.
Baris Yildiz

baris104@yahoo.com

1

Ankara Numune Teaching Hospital, Ankara, Turkey 